\title{
Effectiveness of face-to-face and webinar combination in increasing understanding on school wellbeing for elementary headmasters in Yogyakarta Special Region
}

\author{
Kartika Nur Fatbiyah'; ${ }^{\prime}$ Diana Setiyawati ${ }^{2}$ \\ Department of Psychology, Universitas Negeri Yogyakarta, Jl. Colombo No. 1, Depok, Sleman, \\ Yogyakarta, Indonesia ${ }^{1}$ \\ Faculty of Psychology, Universitas Gadjah Mada, Jl. Sosio Humaniora Bulaksumur, Depok, Sleman, \\ Yogyakarta, Indonesia ${ }^{2}$ \\ kartika@uny.ac.id'; diana@ugm.ac.id²
}

\begin{abstract}
This research aims to determine the effectiveness of face-to-face and webinar combination in increasing elementary school headmasters' comprehension on School Wellbeing in Yogyakarta Special Region. This study used a quasi-experimental design. The subject of the research is 29 elementary school headmasters across Yogyakarta Special Region (abbreviated as DIY) that have participated in pretest, initial face-to-face session, webinar sessions, final face-to-face session, and posttest. The data analysis used t-test analysis using SPSS version 21 to analyze School Wellbeing, pre and post training. The result of the research shows that the combination of face-to-face and webinar sessions is proven effective to increase the comprehension on School Wellbeing of elementary school headmasters across DIY. However, after being reviewed from the process, the training session needs to be revised considering that many of the participants did not follow the entire session due to the clashing of participants' personal schedule and training session.
\end{abstract}

Keywords: face-to-face, headmaster, school wellbeing, understanding, webinar

\section{Introduction}

Society typically agrees that school creates a path to a better future through academic achievements. In Indonesia, it is common for academic achievement to be the benchmark for both elementary to higher education student and school's success. Students with high national exam scores will receive more acknowledgment from family, school, and society. Their school will also be viewed as a top rank school among society. Therefore, parents and teachers actively support students in gaining high academic achievement, one of which is through their efforts to prevent mockery, marginalization, or feeling of guilt on students with poor academic achievement (Zhang, Tze, Buhr, Klassen, \& Daniel, 2015). The school's high expectation contributes to the high negative emotion that students experience (Verma et al., 2002).

Meanwhile, various research argued that the role of schools is not limited to creating a better future life. Instead, their most important role is to increase the wellbeing of children and teenagers (Hamilton \& Redmond, 2010). Watson et al. (2012) found that teachers and students perceive school as an essential place to build interpersonal relationships. In this case, well-being is seen within the context of relation. In other words, students, school employees, and teachers go to school because they need other people. According to a qualitative study by Thomas (2016), people desire to receive recognition, characterized by being known personally, cared for, understood, respected, and valued through their achievement and contribution. These are all aspects that students should expect to receive from their teacher, fellow students, and family.

Similarly, Dehuff (2013) found that students' relationship with teacher, school staff, and fellow students is an essential factor to actualize their well-being. The relation between students and school will grow stronger when the former feels well-known 
personally, recognized, and noticed, allowing them to consider the school as their family. The above studies highlighted the importance that all parties understand and optimally apply school wellbeing to develop their students' potential.

Various journals and literatures have socialized and emphasized the importance of broadly implementing the concept of 'School Wellbeing' at schools. On the field, the society's understanding about School Wellbeing is still limited. Both teacher (key implementer of education at school) and headmaster (one of the authority figures in determining the school's internal regulation) have not thoroughly understood the concept of School Wellbeing (Setiyowati \& Hamsyah, 2016). A formal visit between CPMH (Center for Public Mental Health) of Universitas Gadjah Mada and the head of Department of Education, Youth and Sports DIY on October 20, 2015 , resulted in an agreement that involving school stakeholders from all educational levels to implement School Wellbeing is important. They also agreed upon the importance of establishing an elaborate and written mental health care system that is evident in school regulations so that School Wellbeing can be achieved.

Mental health improvement program exists in both junior and senior high school. However, no mental health program is found at the elementary school level even though it is one of the most significant educational phases in teaching values. A good school mental health system, which is particularly seen through its' rules and regulation that support School Wellbeing, is expected to prevent student problems in the future. Socialization about mental health issues from elementary to higher education level is a strategic step towards School Wellbeing Indonesia (Setiyowati \& Hamsyah, 2016).

A survey on elementary school headmasters in DIY found that schools that support their students' wellbeing will have adequate physical facilities, alongside high standard of security and comfort for the students, with a real benchmark. Based on discussion and survey, it became apparent that expanding the elementary school headmas- ters' knowledge and capability regarding leadership and school management are important steps to the actualization of School Wellbeing (Setiyowati \& Hamsyah, 2016).

One of the efforts to equip headmasters with the knowledge and skills on school management that support School Wellbeing is through a combination of face-to-face and webinar teaching method. This combination allows them to cover each of their weaknesses. Face-to-face method is considered valid because the learning process can be done directly, allowing several School Wellbeing strategies to be conveyed and discussed. It also enables thought exchanges about how each school implemented and actualized their School Wellbeing. Participants can ask questions if they have difficulties understanding the materials. However, considering the limitation of time and place, the method should be combined with another to strengthen the headmasters' School Wellbeing capacity optimally. Thus, the webinar was chosen as the perfect method.

The webinar is an interactive training session done through the internet (Moorhead, 2009). Stein et al. (2010) added that webinar is an online interactive seminar at a predetermined time. It differs from a webcast in that information can be exchanged both ways. In other words, the audience can initiate real interaction with the instructor (Moorhead, 2009). It has been increasingly popularized for the past few years in the educational setting. The connection on a webinar is made for easy use through its' neat design. Webinar audience are only required to click a particular link to be instantly connected with an online meeting room. Meanwhile, others without access can listen to the webinar through a phone call. Further, it is equipped with a recorder and chat pod application, allowing participants to interact amongst each other, as well as with the instructor, without interrupting the discussion (Grant, 2009). Malik et al. (2015) tried to explore engineers' reception towards webinar based on four aspects, namely (1) perceived benefit, (2) ease of use, (3) efficacy method and (4) intention in using. The research result shows that the convenience of using webinar and efficacy method relates positively to the 
intention of using webinar. The easier it is for people to use webinar; the more people intend to use webinar.

The essential components of webinars include audience, presenter, facilitator, presentation, and software used during the webinar process. The webinar steps are (1) planning (invitations sent to the applicants), followed by registration process to obtain applicants according to plan, (2) delivery and (3) post-mortem, a closing statement that thank the entire participants as well as relay the webinar result to all team members. On a successful webinar, each component and process function optimally in building a dynamic interaction between participants (Moorhead, 2009).

Several tryouts have been done to test the effectiveness of webinar; showing positive results. A research done by Agnes (2012) showed that the involvement in webinar predicts students' behavior and involvement in online learning, whether based on experience nor through a positive change of mindset. Webinar students are satisfied with the webinar discussion, feeling more connected with fellow participants.

In training professional clinical researchers, the use of synchronous webinar was found to be effective in educating clinical participants to report adverse events. The participants report that high satisfaction level towards webinar method is related to accessibility, range, quality, and interactivity towards the program to expand their professional ability (Borgenson \& Dino, 2012). Reinke et al (2012) also prove that end of life care on COPD (Chronic Obstructive Pulmonary Disease) can be well received through webinars. Moss et al. (2012) found that webinar could increase the number of teenagers who receive vaccination in the last month.

Although several types of research have proven the effectiveness of webinar method, Hudman et al. (2015) seem to have found a contradictive result. On CPE (Continuing Pharmacy Education): Do Ask, Do Tell activity, an approach to stop smoking habit is more useful to be given through face to face method than a webinar. Similarly, Sargeant et al. (2006) also found that webinar could not build a sense of togetherness compared with face to face discussion. Online learning process often causes the disconnected feeling, whether observed from the material side, participant side, facilitator side, or feedback side.

Based on the research, the combination of face to face and webinar is assumed to complement each other as a method to increase the knowledge of School Wellbeing. We aim to test the effectiveness of the face to face and webinar combination in increasing headmasters' comprehension of School Wellbeing. There is a difference in the elementary school headmasters' level of comprehension of School Wellbeing before and after the combined face-to-face and webinar training, in that the comprehension level after training is higher than before training.

\section{Method}

This is a quasi-experimental research, defined as an experiment that has action and measurement of experiment unit impact without the use of random assignment, creating a comparison to conclude changes caused by the action (Cook \& Campbell, 1979). The quasi-experiment method was used because training process cannot be controlled.

We began the research by conducting a pretest to measure the headmasters' initial knowledge about the concept and application of School Wellbeing. Next, lecture and a short training on webinar were conducted. Webinar was consecutively conducted for four times for four weeks in the following week and ended with a final face to face meeting to sharpen the concept and application of School Wellbeing. This is done to pull a conclusion out of the activities. We also conducted a post-test to measure the participants' understanding of the concept and application of School Wellbeing.

The subject of the research is 29 headmasters throughout DIY who have followed pretest, initial face to face session, webinar sessions, and final face to face session. During the initial face to face session, there were 80 headmasters throughout DIY, consisting of 20 people from Bantul district, 20 from Kulon Progo district, 20 from Gunungkidul 
district, and 20 from Yogyakarta. Headmaster representatives from Sleman district were not present due to administrative reasons. However, because the training participants who fully completed pretest and posttest and following webinar sessions are only 29 participants, therefore the headmasters that become the subject of this research are only 29.

Based on Table 1, it can be concluded that the Comprehension Scale about School Wellbeing on elementary school headmasters measures their concept and practical comprehension on School Wellbeing. Concept comprebension is an understanding about the concept of School Wellbeing that includes (a) essential component of academic achievement (no. 1), (b) reward and punishment system and strategy for the students (no. 2 and 4), (c) perception towards students' potential (no. 3), and (d) perception towards students with special needs (no. 9). Practical comprehension is an understanding of the implementation of the School Wellbeing concept at school. Practical understanding includes: (a) recognition and treatment towards the students with mental problems (no. 5, 6, and 10), (b) ability to build a habit of respecting each other (no. 7), and (c) ability to detect student's mental health problem (no. 8).

Table 1 also shows 10 points of statements in a scale, consisting of seven favorable and three unfavorable questions. The scores for the favorable questions are 1 (very less), 2 (less), 3 (moderate), 4 (good), and 5 (very good). Meanwhile, the scores for unfavorable questions are 1 (very good), 2 (good), 3 (moderate), 4 (less) and 5 (very less).

A total of 80 questionnaires were handed out to the participants. During the posttest, only 29 questionnaires were collected. Thus, only 29 questionnaires could be analyzed to explore the elementary school headmasters' different level of understanding School Wellbeing before and after training. The data were analyzed using quantitative analysis with T-test using SPSS 21 program to measure differences between headmasters' comprehension on School Wellbeing before and after training.

\section{Training Procedure}

The training titled 'Visionary Headmaster Forum' was conducted on November 10, 2015, using face to face method during the initial process. It presents materials about the concept of School Wellbeing by Prof. Dr. Amitya Kumara, M.Si (psychologist), and Leadership with Positive Work Attitude by Drs. Sumaryono, M.Si.

After the first face to face lecture session, training was followed by a webinar session one week later. It was consecutively done for four weeks with the following detail: The first webinar was conducted on November 18 , 2015. The webinar emphasizes the importance of school's role in securing and optimizing student's mental health, which was presented by Dr. Diana Setiyawati; followed by 40 headmasters. The second webinar was conducted on November 26, 2015, with the material about the importance of appreciation towards the whole school system which was presented by Nurul Kusuma Hidayati M.Psi., Psi and Fuad Hamsyah, M.Sc; followed by 20 headmasters. The third webinar was conducted on December 2, 2015, emphasizing the importance of observing learning process from the student's point of view as a teacher (from the development characteristic and the student's individual difference), presented by Kartika Nur Fathiyah M.Psi., Psi. and Dr. Diana Setiyawati; followed by 17 participants.

Table 1. Framework of comprehension scale and school wellbeing implementation on elementary school headmasters in DIY

\begin{tabular}{cccc}
\hline No & The Revealed Aspects & No. favorable item & No. favorable item \\
\hline 1. & Concept Comprehension & 3,4 & 1,2 \\
2. & Practical Comprehension & $5,6,7,8,9$ & 10 \\
& Total & $\mathbf{7}$ & $\mathbf{3}$ \\
\hline
\end{tabular}


The fourth webinar was conducted on December 9, 2016. The material describes the leadership that is expected from visionary headmasters, which was presented by Farah Aulia M.Psi., Psi. and Nurul Kusuma Hidayati M.Psi., Psi; followed by ten headmasters.

The sequence of a webinar for four weeks was later closed with a face to face seminar conducted on December 16, 2015. The speaker was Prof. Djamaluddin Ancok, Ph.D. with the theme about how to face difficult school elements, and Yuli Fajar Susetyo, S.Psi., Psi., M.Si. with the theme of headmasters that are prospering the school. The number of participants who were present was 41 participants.

\section{Findings and Discussion}

Findings

Analysis of research sample can be seen on Table 2. Table 2 shows that the total mean of pretest was 39.79 and posttest mean is 42.52. Further, the analysis about the difference between pretest and posttest can be seen in Table 3.

Based on Table 3, it can be concluded that based on the correlation between pretest and posttest 0.551 and significance number 0.002 . Because the probability is $<0.05$, thus nil hypotheses are rejected. Therefore, between pretest and posttest has a significant relation. This result shows that there is a significant difference between headmaster's comprehension level about School Wellbeing between pre and post training. Observing from the mean, the total of posttest mean score is 42.52 , meanwhile the total of pretest score mean is 39.79 . This result shows that posttest result is better than pretest.

\section{Discussion}

Our findings reveal that the elementary school headmasters' knowledge on School Wellbeing is higher after the face-to-face and webinar combination training. This result supports the previous explanation that face-toface and webinar method combination could complement each method's weakness, making it an effective strategy to increase comprehension. The chance to interact in real life with the presenter can be facilitated through the webinar (Moorhead, 2009) and face-to-face session. In other words, participants can raise questions or arguments about things that puzzle them. The combination of face-to-face and webinar could accommodate participants who came from other regions. Participants are still able to follow the material and interact with the presenter during the webinar session at their respective school location. Thus, solving the issue of time and space limitation.

As a whole, the training went according to the objective of the program. The participants showed high enthusiasm by actively raising questions and engaging with the training program. This program made all the parties aware of the need for more forums intended for sharing and consultation, as well as increase the headmasters' knowledge and skill regarding leadership and school management. A clear implication of this program is the creation of School Wellbeing program in one of the participating schools namely Sendang Sari State Elementary School, located in Pajangan, Bantul.

Although face-to-face and webinar combination training prove to be effective in increasing headmasters' comprehension about School Wellbeing, several limitations of this training need to be improved to ensure opti-

Table 2. Paired samples statistics

\begin{tabular}{llcccc}
\hline & & Mean & N & Std. Deviation & Std. Error Mean \\
\hline \multirow{2}{*}{ Pair 1 } & Pretest & 39.79 & 29 & 4.021 & .747 \\
& Posttest & 42.52 & 29 & 4.163 & .773 \\
\hline
\end{tabular}

Table 3. Paired samples correlations

\begin{tabular}{ccccc}
\hline & & N & Correlation & Sig. \\
\hline Pair 1 & Pretest \& Posttest & 29 & .551 & .002 \\
\hline
\end{tabular}


mal training. A few technical problems include weak internet connection and participants' lack of experience in using the webinar program. However, these technical problems were handled well during the actual program, preventing any significant interruption.

There were differences between the number of participants who participated in the face-to-face and webinar sessions. More participants were found in the face-to-face compared to webinar session. This may be explained by the time and technical constraint regarding the webinar, causing an inconsistent number of participants. However, more questions could be accommodated and answered in the webinar session.

It is crucial to choose appropriate timing for both training and monitoring of the participants to ensure a consistent number of participants. It would also help to ensure that participants are implementing the training program consistently and correctly. Participants who are not able to follow the webinar session could access the recording of the session from the facilitator.

\section{Conclusion and Feedback}

This activity could increase the awareness of headmasters in Yogyakarta about the importance of school in developing student's mental health, also known as School Wellbeing, a school system that promotes a sense of ease and belonging.

Webinar method is suitable for this training series, giving headmasters the chance to follow the training session without having to come directly to the seminar. It also minimizes cost and provides a more flexible time to answer questions thoroughly. Several technical problems existed, but none caused significant problems.

The benefit of this activity is that headmasters are more aware of the importance of forming School Wellbeing and their role in actualizing the program within their respective schools. From this training session, headmasters also have a forum to share each other's stories and consult about the cases that occurred in their school.

Future activities could focus on increasing the educational level of the headmasters and number of participants, both during the face to face or webinar. A step-by-step webinar activation guide should be made to be communicated during face-to-face session or in the form of a soft-file that could be accessible at any time to limit technical issues.

\section{References}

Agnes, W.S.K. (2012). Relationship between participation in the webinar \& students' behavior \& engagement in online learning. Thesis. Canada, Toronto: University of Toronto.

Borgenson, D. \& Dino, J. (2012). The feasibility, perceived satisfaction, and value of using synchronous webinars to educate clinical research professionals on reporting adverse events in clinical trials: A report from the children's oncology group. Journal of Pediatric Oncology Nursing, 29(6), 316-322.

Cook, T.D. \& Campbell, D.T. (1979). Quasi experimentation: Design and analysis issues for field setting. Boston, MA: Houghton Mifflin.

Dehuff, P.A. (2013). Student's wellbeing \& sense of belonging: A qualitative study of relationship and interactions in a small school district. Dissertation. Washington, WA: Washington State University.

Grant, A. (2009). Webinars at Lousiana Virtual School. Principal Leadership, 9(9), 64-66.

Hamilton, M. \& Redmond, G. (2010). Conceptualization of social emotion wellbeing for children, young people, \& policy implications. Sydney, NSW: Social Policy Research Centre.

Moorhead, C. (2009). Getting the most from a webinar event. Security Dealer \& Integrator, 38-39.

Reinke, L.F., Griffith, R.G., Wolpin, S., Donesky-Cuenco, D.A., Kohlman, V.C., \& Nguyen, H.Q. (2011). Feasibility of a webinar for choaching patients with Chronic Obstructive Pulmonary Disease on end of life 
communication. American Journal of Hospice \& Pallative Medicine, 28(3), 147 152.

Stein, G.H., Shibata, A. Bautista, M.K., \& Tokuda, Y. (2010). Webinar: An initial experience with web-based real time interactive clinical seminars for Japaneese medical students. General Medicine, 11, 87-90.

Setiyawati, D. \& Hamsyah, F. (2015). Webbased training: Being a visionary principalMenjadi kepala sekolah visioner. Report of Community Service Grant. Yogyakarta: Fakultas Psikologi UGM.

Thomas, N. (2016). Conceptualizations of children wellbeing at school: The contributions of recognition theory. Childhood, 1-5.
Verma, S., Sharma, D., \& Larson, R.W. (2002), School stress in India: Effects on time and daily emotions. International Journal of Behavioral Development, 26(6), 500-508.

Watson, D., Emery, C., \& Bayless, P. (2012). Children's social \& emotional wellbeing in schools: A critical perspective. Bristol: Policy Press.

Zhang, X.. Tze, V.M.C., Buhr, E., Klassen, R.M., \& Daniels, L.M. (2015). A crossnational validation of the academic expextations stress inventory with Chinese and Korean high school students. Journal of Psychoeducational Assesment, 1-7. doi: $10.1177 / 0734282915599460$. 